\title{
Validation of Cone Beam CT Scan for Measurement of Palatal Depth in Study Casts
}

\begin{abstract}
The purpose of this study was to validate the use of digital dental study casts obtained from Cone beam CT Scan (CBCT) against gold standard; that is traditional dental study cast measured with digital caliper.

Thirty-four study casts of Malaysian Aborigines were selected from Centre of Malaysian Pribumi Studies Databank. Palatal depth of each study casts were measured using Mitutoyo digital caliper. Subsequently, all the study models were scanned using iCAT CBCT and the palatal depth were measured using i-CAT software. Data were analysed using SPSS version 12.0 where Intraclass correlation and paired T-test were employed.
\end{abstract}

There was no significant difference in palatal depth between CBCT and Mitutoyo digital caliper $(p>0.05)$. Average measures for Intraclass Correlation is 0.753 indicate that it is consistently good.

Within the limitation of this study palatal depth measurement produced by CBCT was as accurate as the digital caliper. However, more samples and parameters should be added to further substantiate the result of this study.

Authors:

Radzi, Z. ; Yahya, N. A. ; Abu Kasim, N. H. ; Abu Osman, N. A. ; Yusof, Z. Y. M. ; Mohd, F. N. ; Noor, N. H. M. ; Jamaludin, M. ; Othman, S. A. ; Obaidellah, U. H. ; Mohamed, N. H. ; Kadir, R. ; Nambiar, P.

Book: $\quad$ 4th Kuala Lumpur International Conference on Biomedical Engineering 2008, Vols 1 and 2

Year: $\quad 2008$

Pages: $\quad 758-761$

\section{Keywords :}

Validation; dental study casts; palatal depth; CBCT \& Digital Caliper PLASTER MODELS; ACCURACY 


\section{Please cite as :}

Radzi, Z., N. A. Yahya, et al. (2008). Validation of Cone Beam CT Scan for Measurement of Palatal Depth in Study Casts. 4th Kuala Lumpur International Conference on Biomedical Engineering 2008, Vols 1 and 2. N. A. AbuOsman, F. Ibrahim, W. A. B. WanAbas, H. S. AbdulRahman and H. N. Ting. Kuala Lumpur, SPRINGER, 233 SPRING STREET, NEW YORK, NY 10013, UNITED STATES. 21: 758-761.

\section{URL :}

http://www.springerlink.com/content/v83t3h0076211674/

http://books.google.com.my/books?id=sdG-

$1 \mathrm{hN}$ 4TYC\&pg=PR21\&lpg=PR21\&dq=Validation+of+Cone+Beam+CT+Scan+for+Meas urement+of+Palatal+Depth+in+Study+Casts\&source=bl\&ots=eL04WIK8U\&sig=tszDV5FVhYRSGRWHxlC3HqOhzdU\&hl=en\&ei=TWThTtHvDcmarAfm LzjAQ \&sa $=X \& o i=b o o k$ result\&ct=result\&resnum $=2 \& v e d=0 C C U Q 6 A E w A Q \# v=0 n e p a g e \& q=V a l$ idation\%20of\%20Cone\%20Beam\%20CT\%20Scan\%20for\%20Measurement\%20of\%20 Palatal\%20Depth\%20in\%20Study\%20Casts\&f=false

http://www.researcherid.com/rid/B-9275-2010 